\title{
Parent and child perspectives on family out-of-home eating: a qualitative analysis
}

\author{
Lynn E McGuffin ${ }^{1}$, Ruth K Price ${ }^{1}$, Tracy A McCaffrey ${ }^{1,2}$, Glenn Hall ${ }^{3}$, Alan Lobo ${ }^{3}$, \\ Julie MW Wallace ${ }^{1}$ and M Barbara E Livingstone ${ }^{1, *}$ \\ ${ }^{1}$ School of Biomedical Sciences, Northern Ireland Centre for Food and Health, University of Ulster, Cromore Road, \\ Coleraine, BT52 1SA, UK: ${ }^{2}$ Be Active Eat Sleep (BASE), Department of Nutrition and Dietetics, Monash University, \\ Melbourne, Victoria, Australia: ${ }^{3}$ Millward Brown Ulster, Belfast, UK
}

Submitted 24 October 2013: Final revision received 16 April 2014: Accepted 6 June 2014: First published online 7 August 2014

\begin{abstract}
Objective: To (i) explore the factors influencing family out-of-home $(\mathrm{OH})$ eating events and (ii) identify possible opportunities for food businesses to support families in making healthier $\mathrm{OH}$ choices.

Design: Focus group discussions were conducted with parents (six to eight participants per group) and friendship pair discussions (informal interviews with two children who are friends) were conducted with children (5-12 years) throughout the island of Ireland. Both discussions were audio-recorded and analysed using a thematic content analysis.

Setting: Eight focus groups and sixteen friendship pairs were conducted in Northern Ireland and sixteen focus groups and thirty-two friendship pairs were conducted in the Republic of Ireland.

Subjects: Purposive sampling was used to recruit a sample of non-related parents and children that represented equal numbers of gender, age, socio-economic status and demographic backgrounds.

Results:: The main, overarching theme was that families perceived $\mathrm{OH}$ eating to be a treat, while health was not currently a key priority for many parents and children. Children were reported to have most responsibility for their own food choice decisions in this environment, with taste and food neophobia having the greatest influences. Parents believed that if food businesses could meet parent and child priorities in addition to health influences, e.g. change cooking methods, and increase flexibility, then families would be more likely to patronise these establishments.

Conclusions: The entire family $\mathrm{OH}$ eating experience needs to be considered when developing public health interventions and this research has highlighted key opportunities that caterers could employ to support healthier family $\mathrm{OH}$ food choices.
\end{abstract}

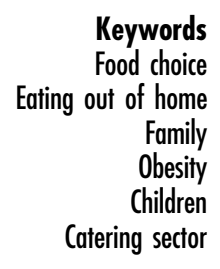

Obesity is a complex, multifaceted public health problem in which the food environment plays a key role ${ }^{(1)}$. Out-ofhome $(\mathrm{OH})$ eating is one aspect of the food environment that is becoming increasingly important in promoting overeating and excess energy intakes. The increasing trend in $\mathrm{OH}$ eating has been well documented in the $\mathrm{USA}^{(2,3)}$, but a lack of consistent data and definition of $\mathrm{OH}$ eating has hindered the identification of any clear trends for the UK and Republic of Ireland (ROI). In the UK, OH eating accounted for $11 \%$ of total energy intakes in $2011^{(4)}$ but the definition of $\mathrm{OH}$ eating was not clear, with the exception of including school and work meals. In ROI, $\mathrm{OH}$ eating contributed $24 \%$ to total energy intakes when restaurants, takeaways, shops and delicatessens were included ${ }^{(5)}$.

In adults, $\mathrm{OH}$ eating has been associated with larger portion sizes ${ }^{(2,6,7)}$ and higher energy intakes ${ }^{(2,6-9)}$ but lower micronutrient ${ }^{(8)}$ and fruit and vegetable intakes ${ }^{(6,9,10)}$. Similar findings have been found for children, suggesting that children who eat $\mathrm{OH}$ frequently have higher intakes of total energy, total fat, total carbohydrate, added sugars and sugar-sweetened beverages with lower intakes of fibre, milk, fruit and vegetables ${ }^{(11,12)}$. Fast-food establishments and restaurants were found to contribute more to total energy intakes (14.8\%) than meals and snacks consumed in schools or day-care centres ( $8.7 \%$ ) by US $2-18$-year-olds ${ }^{(3)}$. 
Therefore, not surprisingly, high consumption of $\mathrm{OH}$ food has been associated with weight gain in children and adolescents (4-19 years) ${ }^{(13,15)}$.

The overall family food environment plays a pivotal role in developing children's eating behaviours and parental eating habits have been correlated with children's eating behaviours ${ }^{(15-19)}$. Furthermore, regular family meals have been associated with lower levels of overweight and obesity $^{(17,20-22)}$, but parents in the USA admitted that eating together as a family occurred more frequently $\mathrm{OH}$ than in the home ${ }^{(23)}$. If similar trends become the norm in the UK and ROI then there is clear scope for supporting families who regularly eat $\mathrm{OH}$ to select more healthy food items, particularly as childhood eating habits and obesity can track into adulthood ${ }^{(18,24)}$. Given that $77 \%$ of Irish children (aged 5-12 years) ate $\mathrm{OH}$ at least once per week in $2004^{(25)}$ and that food establishments offer meals specifically for children, the $\mathrm{OH}$ eating context for children should be a key focus for public health. There has been an increased understanding of what influences children's food choice decisions at home including taste, hunger, advertising, availability of food, body image and peers (e.g. references 26-29), but little is known about the role of these factors when children eat $\mathrm{OH}$. A better understanding of family $\mathrm{OH}$ eating will help to plan future public health strategies in this complex eating context. The WHO has advocated the inclusion of all stakeholders in public health policies and interventions ${ }^{(30-32)}$ and there appears to be a willingness among $\mathrm{OH}$ caterers to engage in healthier eating initiatives, provided consumers find these acceptable $\mathrm{e}^{(33,34)}$. However, little is known about the motivation for families to make healthier $\mathrm{OH}$ food choices and clarification of this issue would help to ensure that public health interventions are likely to be effective.

Therefore the aim of the present paper was twofold: (i) to explore the factors influencing family $\mathrm{OH}$ eating events; and (ii) to identify possible opportunities for food businesses to support families in making healthier $\mathrm{OH}$ choices. For this purpose, family $\mathrm{OH}$ eating has been defined as any food or beverage that has been cooked outside the family home for a family to eat together, including takeaways but not including ready meals purchased in a supermarket ${ }^{(35)}$.

\section{Methods}

Qualitative research methods were selected for an indepth exploration of the factors influencing family $\mathrm{OH}$ eating. Both parents and children participated in the research to gain a more complete perspective of family dynamics when eating $\mathrm{OH}$ together. To maximise the range of family perspectives obtained in the research, parents and children were not related. Focus group discussions were selected for parents as the most appropriate method of encouraging parents to interact and obtain a better understanding of their perspective of family $\mathrm{OH}$ eating. Friendship pair discussions involve two children who are friends and were selected as the most appropriate method of encouraging communication with this age group $^{(36)}$. In addition, the moderator is able to redirect questions between the children and encourage them to discuss questions between themselves ${ }^{(37)}$ while avoiding the potential for biased responses that might occur as a result of either peer pressure in larger groups or in one-to-one interview situations. The study was conducted according to the guidelines laid down in the Declaration of Helsinki and all procedures involving human participants were approved by the University of Ulster Research Ethics Committee (REC/ 11/0057). Written informed consent was obtained from parents and children.

\section{Recruitment}

Purposive sampling was used to recruit parents (of children aged 5-12 years) and children (aged 5-12 years) from the island of Ireland during June-August 2011. Inclusion of children and parents of children aged 5-12 years was selected so as to incorporate those most likely to be targeted by children's menus when eating $\mathrm{OH}$. A market research company was engaged to recruit a sample of parents and children by face-to-face methods. Both parents for the focus groups and parents of children for the friendship pairs completed a short characteristics questionnaire to ensure participants represented equal numbers of gender, age (parents $<35$ years, $\geq 35$ years; children aged 5-6 years, 7-8 years, 9-10 years, 11-12 years), socioeconomic status (high and low) and demographic backgrounds (location on the island of Ireland). If a respondent met the desired criteria for that session, he/she was formally invited to take part. Parent and child characteristics of those who participated are displayed in Tables 1 and 2 .

\section{Focus group (parents) protocol}

Twenty-four ( $n 8$ in Northern Ireland; $n 16$ in ROI) mixedgender (with the exception of one all-female) focus group discussions were conducted (six to eight participants in each group), each lasting approximately $90 \mathrm{~min}$. The discussion topics are listed in Table 3 and were based on previous literature on food choice in the home and discussions by the research team; however, the schedule was also flexible to allow parents to raise issues of importance to them.

One of three experienced moderators facilitated the discussions (A.L., N.B., D.M.), which were held in informal settings convenient to participants. A note taker was also present but did not participate (L.E.M., R.K.P.). At the outset, the moderator explained that the discussions were concerned with family experiences of eating $\mathrm{OH}$ but no explicit reference was made to nutrition or health. Parents were asked to introduce themselves and as an ice-breaker reported how many children they had and where they liked to eat $\mathrm{OH}$ as a family. The moderator encouraged participation from all parents and prompted elaboration on 
issues related to the discussion guide or unanticipated but relevant topics. An honorarium was given to parents for time and travel costs (£30).

\section{Friendship pair (children) protocol}

Forty-eight ( $n 16$ in Northern Ireland; $n 32$ in ROI) friendship pair discussions were conducted with children of the

Table 1 Characteristics of focus group participants: purposive sample of parents (of children aged 5-12 years) from the island of Ireland, June-August 2011 (n 186)

\begin{tabular}{lrl}
\hline Characteristic & $n$ & $\%$ \\
\hline Gender & & \\
$\quad$ Male & 82 & 44 \\
$\quad$ Female & 104 & 56 \\
Age of parent/guardian & 92 & 49 \\
$\quad \geq 35$ years & 94 & 51 \\
$\quad<35$ years & 92 & 49 \\
Socio-economic status & & 51 \\
$\quad$ High & 94 & \\
Low & & \\
\hline
\end{tabular}

*Market Research Society grading of occupations: high, occupations categorised as A, B and C1; low, occupations categorised as C2, D and $E^{(48)}$.

Table 2 Characteristics of friendship pair discussion participants: purposive sample of children (aged 5-12 years) from the island of Ireland, June-August 2011 ( $n$ 96)

\begin{tabular}{lll}
\hline Characteristic & $n$ & $\%$ \\
\hline Gender & & \\
$\quad$ Male & 48 & 50 \\
Female & 48 & 50 \\
Age (years) & & \\
$5-6$ & 24 & 25 \\
$7-8$ & 24 & 25 \\
$9-10$ & 24 & 25 \\
$11-12$ & 24 & 25 \\
Socio-economic status & & \\
High & 48 & 50 \\
Low & 48 & 50 \\
\hline
\end{tabular}

*Market Research Society grading of occupations: high, occupations categorised as A, B and C1; low, occupations categorised as C2, D and $E^{(48)}$. same age and gender. Each lasted 15-30 min, depending on the motivation and ability of the child to engage in the discussion (i.e. discussions times were curtailed if the children were distracted and not willing to participate fully). A semi-structured discussion guide (Table 3) was developed to complement the discussion guide developed for the focus group discussions, but it was also flexible to tailor the discussions to the children's cognitive ability (i.e. younger children were unable to recall information, such as establishment names) and interest.

One of three experienced moderators facilitated the discussions with children (A.L., N.B., D.M.) and a note taker was also present during the discussions (L.E.M., R.K.P.). Parents were invited to sit in on the discussions if they wished but did not participate in the discussions. As an ice-breaker children were asked where their favourite places to eat $\mathrm{OH}$ were and what foods they liked to order $\mathrm{OH}$. The moderator encouraged both children to participate and discuss issues between themselves. When all of the topics in the discussion guide were addressed children completed a quiz to facilitate further discussion. Children were presented with seven word pairs of food typically available $\mathrm{OH}$, one of which was considered to be 'healthy' and the other 'less healthy' (Table 3). They were initially asked to select which food they preferred and then which one they perceived as being 'healthier'. At the end of each friendship pair discussion an honorarium in the form of a book token was given to each participating child (£10 for each child, £10 for parent to cover travel costs).

\section{Analysis}

Focus group discussions were audio-recorded and professionally transcribed verbatim, with researchers present as note takers checking transcripts for accuracy with original recordings and field notes (L.E.M., R.K.P.). Friendship pair discussions were audio-recorded and field notes were taken throughout. Transcripts were analysed using a thematic analysis, as described by Braun and Clarke ${ }^{(38)}$,

Table 3 Semi-structured discussion areas for focus groups and friendship pair discussions

\begin{tabular}{|c|c|}
\hline Focus groups (parents) & Friendship pair discussions (children) \\
\hline $\begin{array}{l}\text { Why do families eat out? } \\
\text { Where families like to eat out-of-home? } \\
\text { What factors influence what they would like their } \\
\text { children to order when eating out-of-home? } \\
\text { What factors do parents perceive influence their child's } \\
\text { food choice when eating out-of-home? } \\
\text { Potential opportunities that would be acceptable for } \\
\text { families to encourage healthier out-of-home eating? }\end{array}$ & $\begin{array}{l}\text { Part 1: Discussion questions } \\
\text { Do children eat out-of-home and why? } \\
\text { Where children like to eat out-of-the home and why? } \\
\text { What type of food they prefer/dislike out-of-home and why? } \\
\text { Do their parents/guardians choose their food for them? } \\
\text { Perceptions and knowledge of healthy food choices } \\
\text { Part 2: Game } \\
\text { Asked in each pair which food they preferred and then which they } \\
\text { thought was healthier } \\
\text { Potato: mashed potato } v \text {. chips } \\
\text { Chicken: chicken breast } v \text {. chicken nuggets } \\
\text { Beef: stew } v \text {. cheeseburger } \\
\text { Fish: roast salmon } v \text {. fish fingers } \\
\text { Drink: milk } v \text {. Coke } \\
\text { Dessert } 1: \text { fruit salad } v \text {. ice cream } \\
\text { Dessert } 2: \text { rice pudding \& tinned fruit } v \text {. chocolate fudge cake }\end{array}$ \\
\hline
\end{tabular}


independently by two researchers (L.E.M., R.K.P.). NVivo 9 software (QSR International Pty Ltd, Doncaster, Victoria, Australia) was used for more effective data management.

Data familiarisation was achieved by repeated reading of the transcripts and listening to the audio-recordings. The focus group and friendship pair transcripts were analysed separately by systematically coding the data under the main discussion topics (to allow main themes for each discussion topic to emerge). A standard coding format was agreed by the two researchers by coding five randomly selected transcripts. Related codes were then independently collated into potential themes and repeatedly reviewed and refined to ensure they reflected the coded extracts and data set as a whole. Theoretical saturation was reached at approximately eighteen transcripts for the focus groups and twenty-four for the friendship pairs. The two researchers discussed the findings and good agreement was achieved on themes, with full agreement being reached after minor clarifications (interrater reliability of 1.00). The agreed themes were checked to ensure there were clear distinctions and the final themes were named and defined. Appropriate extracts from the focus groups and friendship pairs were selected and agreed to support the final themes.

\section{Results}

The main theme that emerged from both parents' and children's discussions regarding reasons for eating $\mathrm{OH}$ was 'as a treat' and for parents the main theme for selecting what establishment to eat in was 'family friendly' aspects. In terms of children's $\mathrm{OH}$ food choices, 'taste and food preference' were paramount, while parents were more concerned with permitting children to have a treat. The themes that emerged from parents' and children's discussions are presented below under the main discussion topics.

\section{Reasons for eating out-of-bome}

Parents reported they predominantly make the final decision for the family to eat $\mathrm{OH}$ and the reasons for doing so are listed in Table 4. The most important motivating factor for parents to decide to eat $\mathrm{OH}$ was to 'treat' their family. Eating $\mathrm{OH}$ was an opportunity for families to eat together and allowed parents to spend quality time with their children without being distracted by cooking or household chores. It was also perceived by parents as a convenient alternative to eating at home where the family has a break from the everyday eating pattern. The comments from the children complemented those of the adults, namely that they eat $\mathrm{OH}$ 'as a treat' and 'to give mummy/daddy a break in the kitchen'.

Another reason cited for eating $\mathrm{OH}$ was the wide range of special offers available and the ready accessibility of a range of eating establishments near family homes. Parents also perceived that the cost of $\mathrm{OH}$ eating was comparable to eating at home, if not cheaper in some cases.

\section{Choice of out-of-bome eating establishments}

After parents initiated the decision for the family to eat $\mathrm{OH}$, they often permitted their children to choose the establishment (Table 4) as a method of ensuring their child was engaged and more likely to finish his/her meal. Parents believed their children selected an establishment based on marketing techniques, such as advertising, free toys and/or the food available.

From the parent's perspective, 'family friendly' aspects of the establishment were of key importance when choosing a location as this would be more likely to ensure the entire family enjoyed the experience in an environment where they all felt comfortable. Parents were attracted to establishments that provided a form of entertainment/ diversion for children, such as colouring pencils, a clown or bouncy castle.

Cost was a major factor influencing parental choice of eating establishment. Knowing the cost of the family meal before entering the establishment (e.g. set menu price, chain establishments) was appreciated by parents as they could budget for the occasion and hoped to avoid extra costs, such as drinks and desserts.

The time available for eating the meal tended to dictate which establishment was selected by the family. When eating $\mathrm{OH}$ for a social occasion, a sit-in restaurant with a slower service time was more likely to be selected. Alternatively, if time constrained, a fast-food type establishment with rapid service was likely to be the choice. In general, establishments with fast service times were preferred by families, particularly parents with younger children, as this helped avoid children becoming bored and possibly disruptive.

Family meals $\mathrm{OH}$ were more enjoyable in establishments that were perceived to be stress free. Therefore parents preferred to patronise establishments where there was previous experience of family enjoyment or somewhere recommended by other families. The nutritional quality of food was of lesser importance to parents when selecting an establishment; treat and enjoyment factors had greater priority for them. A better standard of food and service was sought when eating $\mathrm{OH}$ for a special occasion, such as a birthday; therefore a full-service restaurant was more likely to be selected by parents on these occasions.

\section{Children's out-of-bome food choice}

Figure 1 is a diagrammatic representation of factors that were reported to impinge upon children's $\mathrm{OH}$ food choice decisions. Parents and children both contributed to a child's final food choice decision (Table 5) and the child's decision has been reported from the parent's and child's perspective. In general, children exerted most control over the final food choice decision and parental 
Table 4 Factors that influence family out-of-home $(\mathrm{OH})$ eating among purposive sample of parents (of children aged 5-12 years) from the island of Ireland, June-August 2011 ( $n$ 186)

\begin{tabular}{|c|c|}
\hline Theme & Quote \\
\hline \multicolumn{2}{|l|}{ Why families $\mathrm{OH}$} \\
\hline Treat & $\begin{array}{l}\text { 'A treat for everyone.' (Parent) } \\
\text { 'So I don't have to cook.' (Parent) }\end{array}$ \\
\hline Time \& convenience & $\begin{array}{l}\text { 'They're a lot handier as well because if you're working all day, you don't want to come home and } \\
\text { start cooking and cleaning up. It's the handiness. And it's laziness.' (Parent) } \\
\text { 'What's easiest to do, put on a pot of pasta or just fly down to the nearest takeaway?' (Parent) }\end{array}$ \\
\hline Cost effective & $\begin{array}{l}\text { 'If you were going to Tesco's or something and buy a packet of burgers and baps and something } \\
\text { else, it works out almost cheaper just to take them to McDonalds.' (Parent) } \\
\text { 'A burger and a pint for a fiver. A lot of the time they're doing so many specials nowadays that you } \\
\text { know, you're thinking why on earth will I cook? Because it's cheaper to go out.' (Parent) }\end{array}$ \\
\hline Range of locations & $\begin{array}{l}\text { 'Everything is easily accessible, you can get anything from the A to Z within five minutes of your } \\
\text { house... In petrol stations there is food on the go.' (Parent) } \\
\text { 'There's so many places - different venues now.' (Parent) }\end{array}$ \\
\hline Family/social time & $\begin{array}{l}\text { 'We don't sit much as a family because I tend to come from work late as well and whatever, and } \\
\text { it's basically the kids get older, it's the one time you can sell it to them to come and have a } \\
\text { meal.' (Parent) } \\
\text { 'And when we go out eating we always make it a family time, we are all together and we all do it } \\
\text { together and we all enjoy it.' (Parent) }\end{array}$ \\
\hline Variety of food & $\begin{array}{l}\text { 'You don't want to get something out you could have cooked at home.' (Parent) } \\
\text { 'Getting them to taste different things that they might not necessarily eat at home.' (Parent) }\end{array}$ \\
\hline \multicolumn{2}{|c|}{ Choice of $\mathrm{OH}$ eating establishment } \\
\hline Child's preference & $\begin{array}{l}\text { 'Wherever they want.' (Parent) } \\
\text { 'I'm fed up going to places and they're just not eating it, so we pick somewhere they like.' (Parent) }\end{array}$ \\
\hline Advertising & $\begin{array}{l}\text { 'It's that big M sign, everywhere you go you see it.' (Parent) } \\
\text { 'Advertising has a lot to do with it - they're all in front of the TV.' (Parent) }\end{array}$ \\
\hline Family friendly & $\begin{array}{l}\text { 'McDonalds is cheap and it is quick and the kids like it and you can always get a highchair and } \\
\text { you can always get a seat... you always end up going back to it, it is probably not the healthiest } \\
\text { thing long term.' (Parent) } \\
\text { 'If the kids are treated well then it will draw the parents in because they don't need to do anything. } \\
\text { (Parent) }\end{array}$ \\
\hline Cost and value for money & $\begin{array}{l}\text { 'Shop around. There's a lot of places that are fighting for competition and they're advertising as } \\
\text { well so if you're going out on a Sunday - you look in the local rag.' (Parent) } \\
\text { 'I think its good the restaurants that have like, a drink and ice cream with the meal. One price.' } \\
\text { (Parent) } \\
\text { 'I wouldn't go to places that would be charging for your squash.' (Parent) }\end{array}$ \\
\hline $\begin{array}{l}\text { Speed of service \& } \\
\text { convenience }\end{array}$ & $\begin{array}{l}\text { 'Carvery I find is much better that they're not getting restless waiting. I don't like going in a } \\
\text { restaurant where the kids are going to be waiting more than fifteen minutes to get something, } \\
\text { because then they get restless and it spoils the whole day going out.' (Parent) } \\
\text { 'As a last resort if its late or we are getting home late with being out and just the kids are tired, } \\
\text { everybody is tired, we will get a McDonalds on the way home.' (Parent) }\end{array}$ \\
\hline Habit/norm & $\begin{array}{l}\text { 'We would have two or three [establishments] that we would go to and we know the kids like the } \\
\text { food there so we will go there.' (Parent) } \\
\text { 'Stick to certain places that I know.' (Parent) }\end{array}$ \\
\hline Quality of food & $\begin{array}{l}\text { 'Most of them that I find don't have the spuds and the half portions... it completely puts me off } \\
\text { going into those places because if I want to give a child nuggets and chips I can do it at home, } \\
\text { it's crap food to be giving anyone.' (Parent) } \\
\text { 'You don't want somewhere that is good value but the food isn't great.' (Parent) }\end{array}$ \\
\hline Occasions & $\begin{array}{l}\text { 'It's [higher end establishments] more special occasions for us now with four boys, and it would } \\
\text { be good exam results but it would really be to a proper restaurant, it would be more on a } \\
\text { special occasion, we eat out quite a lot at McDonalds or KFC whatever, that would be a norm } \\
\text { maybe once a week.' (Parent) } \\
\text { 'Now if we were going for a birthday meal or a celebration, yes, my kids would eat the three } \\
\text { courses.' (Parent) }\end{array}$ \\
\hline
\end{tabular}

input varied depending on the age of the child, with younger children given less control. It was evident that children have their own opinions about what affects their food choice decision and these were first and foremost 'taste/food preference' followed by 'cost/value for money' and 'health and sport'. Parents also provided insight into the factors they believed influenced their children's food choice decision and these were 'marketing', 'presentation of food' and 'significant others'. The only common factor reported by both parents and children as influencing a child's decision was 'the norm/food neophobia', whereby children were afraid to try new foods or when foods were presented differently; therefore they preferred to select foods they were familiar with. Factors influencing parental input were 'treat', 'avoid waste', 'avoid an argument' and to a lesser extent 'health'.

Locations on the island of Ireland (North/South, rural/ urban), age of parent and socio-economic status were not found to affect the factors involved in children's OH food choice, but age of child, and in some cases gender, may 


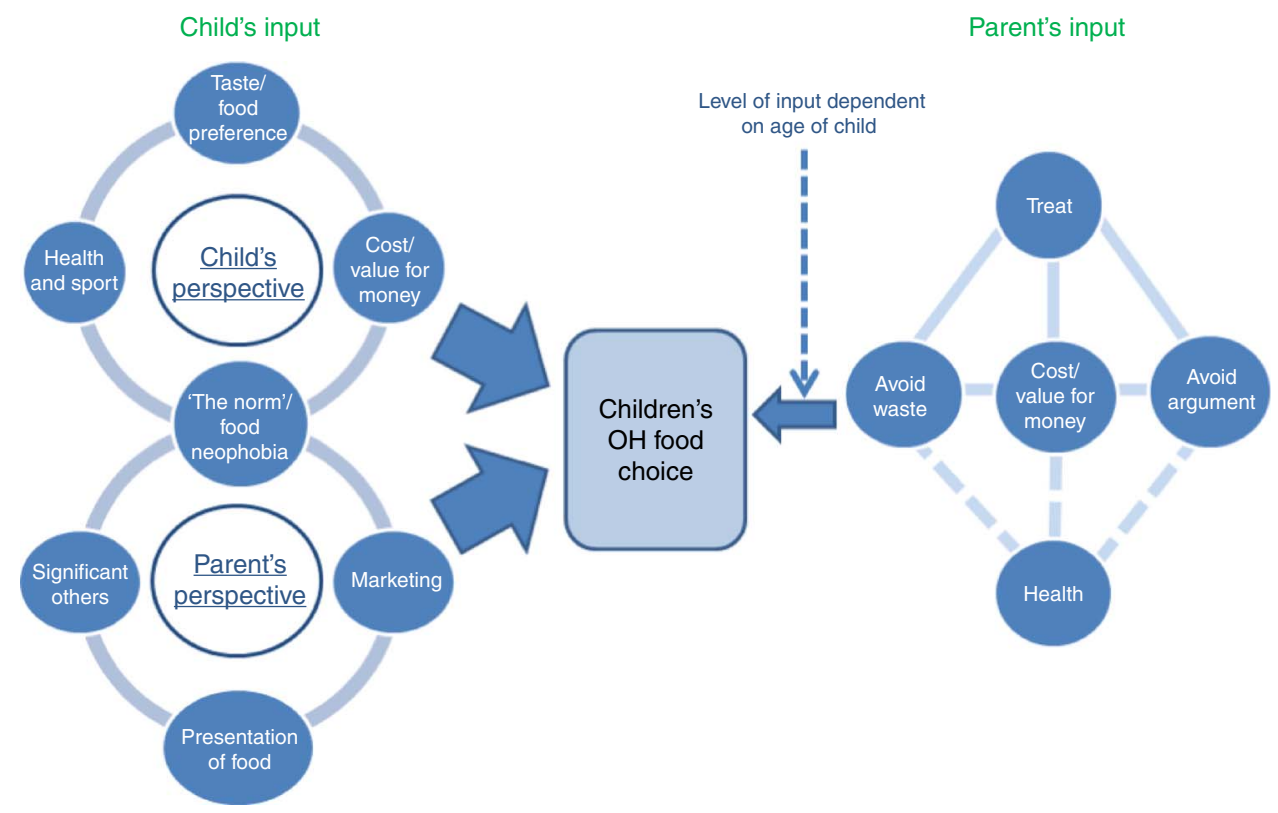

Fig. 1 Factors impinging on children's out-of-home $(\mathrm{OH})$ food choice decisions. Both parents and children contributed to the $\mathrm{OH}$ food choice decision, therefore factors influencing food choice are grouped under 'Parent's input' and 'Child's input'. Parental input varied depending on the age of their child and in general children had most responsibility for the final decision, as indicated by the larger arrows. The child's input was investigated from the parent's and child's perspective in focus groups and friendship pair discussions respectively and the only common factor reported by both parents and children was 'the norm'/food neophobia. Factors influencing the parental input were prioritised with 'treat' having the strongest influence, followed by 'avoid waste' of food, 'cost/value for money' and 'avoid argument' with their children on a similar priority level ( - ). These all were more important than 'health' and the dashed lines $(--)$ indicate 'health' was only considered if these other priorities were satisfied

have influenced the priority of themes. For example, older girls may be given more control over their own food choice decisions than boys of the same age:

'Girls [start choosing themselves] at 4. The boy you would get away with [telling him what to order up to] 9 or 10.' (Parent)

'Give them less choice the younger they are. I mean they can't read the menu.' (Parent)

'I might try with the younger ones, I'll try and steer them towards something more healthy but the older [children] - I have no say.' (Parent)

Child's contribution to out-of-home food choice decision Child's perspective. From the child's perspective, the most important factor that influenced their food choice decision was taste/food preference (Table 5). Food neophobia was another major factor found to contribute to a child's food choice decision and was reported by both parents and children. Overall, children discussed ordering familiar foods that they like the taste of, irrespective of the type of establishment they were discussing. Chinese and foods from carveries and buffets were the only instances when children recalled a wider variety of foods such as roast meats, potatoes, vegetables, curries, spicy chicken and rice.
For older children ( $>11$ years) who ate $\mathrm{OH}$ with their friends as a social event, cost and value for money impacted on their food choice. These factors were largely irrelevant when they ate $\mathrm{OH}$ with parents.

There were conflicting reports from children with regard to health issues for eating $\mathrm{OH}$. Some older children ( $>8$ years) discussed the importance of 'healthy food' in relation to sport and how this might affect their choice. However, the quiz demonstrated that the main reason for children liking a food was taste preference, with health implications or 'healthiness' having minimal impact. Children categorised foods as 'good' and 'bad' and all children perceived 'good' foods as anything that was, or contained, fruit, vegetables, milk and water. Knowledge of health increased with child age and older children were able to explain in more detail why foods were healthier:

'Fish fingers are healthy, they are fish.' (Boy, age 5-6 years)

'Salmon is better because fish is good for the brain and fish fingers aren't [healthy] because they're fried.' (Girl, age 11-12 years)

'Milk's good because it's healthy.' (Girl, age 5-6 years)

'Milk is healthier as it's full of calcium which is good for like your bones and teeth.' (Boy, age 11-12 years) 
Table 5 Factors that influence child and parental input into the child's final out-of-home food choice decision among samples of children (aged 5-12 years; $n$ 96) and parents (of children aged 5-12 years; $n$ 186) from the island of Ireland, June-August 2011

\begin{tabular}{|c|c|}
\hline Theme & Quote(s) \\
\hline $\begin{array}{l}\text { Child's input } \\
1 . \text { Child's perspective }\end{array}$ & \\
\hline Taste/food preference & $\begin{array}{l}\text { 'Healthy food is not as exciting as it's not sweet and doesn't taste nice. Like apples are nice but } \\
\text { chocolate is absolutely gorgeous.' (Child) } \\
\text { 'It's taste that children care about.' (Child) } \\
\text { 'I know Coke is bad but I drink it anyway, it's too good to resist.' (Child) }\end{array}$ \\
\hline 'The norm'/food neophobia & $\begin{array}{l}\text { 'I always get the same thing in case I order something and don't like it.' (Child) } \\
\text { 'Sometimes I like things and then don't.' (Child) }\end{array}$ \\
\hline Cost/value for money & $\begin{array}{l}\text { 'My mum gives me a fiver and I get something big at } £ 4.99 \text { so I don't have anything left over.' (Child) } \\
\text { 'I get } £ 3-£ 5 \text { but I only get something small and a McFlurry so I have money left over.' (Child) } \\
\text { 'Superchip is cheap [so you have money left over] so you can get other things.' (Child) }\end{array}$ \\
\hline Health and sport & $\begin{array}{l}\text { 'Places don't sell healthy food and they should. My mum doesn't let me get the carrots because she } \\
\text { doesn't have enough money always but dad does.' (Child) } \\
\text { 'McDonalds is nice but unhealthy and you get fat if you eat unhealthy.' (Child) } \\
\text { 'I need to eat healthy to make me bendy for gymnastics.' (Child) }\end{array}$ \\
\hline
\end{tabular}

2. Parent's perspective 'The norm'/food neophobia

Marketing

Presentation of food

Significant others

Parent's input

Treat

Avoid waste

Avoid argument

Cost/value for money

Health
' $99 \%$ of the time you know what everyone's going to eat before you even go there anyway.' (Parent) 'She keeps on saying too I don't like that, and I say you have never tried it how do you know you don't like it? I think kids look at something and if it doesn't look right [they don't like it].' (Parent)

'But it was so annoying... I would say to them can I just have plain vegetable and they would be like well it is already made and I would be sitting up and going I am trying to teach my children to eat healthy, you are not helping.' (Parent)

'l'd watch him, and this particular McDonalds ad used to come on, and he'd just glaze over.' (Parent)

'They tend to focus on the toy and they end up not eating what's in the blooming meal.' (Parent)

'I took my girl into Subway and she just sees the cookies with the Smarties on them... I think it is the colour that attracts her or the drinks with the big cups because they're so coloured.' (Parent)

'Somewhere I saw they had done apple slices the same as chips like in a wee packet so they had cut them up in the same way as chips could be.' (Parent)

Parents: 'Imagine if you never went to McDonalds and told the child "No you are never going to McDonalds" and then they go into school and say "l've never been to McDonalds".' (Parent)

Parents: 'You realise as the kids get older they don't do as you say, they do as you do. So you have to eat healthily for them to follow.' (Parent)

Peers: 'They are also enticed with what their friends do. If their friends all get the bottle [of sugarsweetened beverage] then they are not going to get a bottle of still water.' (Parent)

Peers: 'They don't ask for it [a healthier option] because they think they would get laughed at, because everyone else is eating chips.' (Parent)

'You go more for a treat... like l'm not going there to nourish my family.' (Parent)

'Your treat as a Mum is not feeling guilty, no point in doing that [eating out] and then feeling bad.' (Parent)

'It is a treat, like you are paying money for it, you might as well at least have them enjoy it, otherwise they would just eat at home if they are going to be miserable.' (Parent)

'Well you are not going to spend money on something they are not going to eat... You might as well throw it in a bin and throw your money in it.' (Parent)

'Or you don't want to get something for the kids that they won't eat, that just drives me insane... at least if he wants to go for the pasta or the pizza instead of the greens, fine.' (Parent)

'I feel I am paying through the nose for it, so I want them to eat it... I certainly don't want them to be going away hungry... so you have to go somewhere else [to buy them food].' (Parent)

'I know they will kick off and make a show of you, that is why I give them whatever they want.' (Parent) 'At the end of the day you're not going to be annoyed with a child in the middle of a restaurant.' (Parent) 'As long as the kids are happy because then you can just relax.' (Parent)

'You are always looking out for deals... good deal for kids.' (Parent)

'I think it's good the restaurants that have like, a drink and ice cream with the meal. One price. A lot of them do that.' (Parent)

'You like a decent portion.' (Parent)

'It is like yes you can have chips but you have to have potatoes as well, so I would order one with one and then swap [so they each have half and half].' (Parent)

'I would say to them to take the juice or the water rather than the fizzy drinks.' (Parent)

'When we are on holiday every night if we are eating out, I would be monitoring that he doesn't have the sausages and chips every night.' (Parent)
Parent's perspective. Parents reported food neophobia was a problem frequently encountered with their children (particularly younger children) but in the $\mathrm{OH}$ environment this was particularly evident. In general, parents believed children's menus were very limited and of lower nutritional quality compared with the adult menu, with processed meats dominating the menu at the expense of healthier items such as fruit and vegetables. However, parents of younger children and 'fussy eaters' appreciated the almost standard nature of children's menus between establishments.

Parents believed marketing techniques used by OH establishments or how food was presented strongly influenced 
Table 6 Potential opportunities to encourage healthier out-of-home eating suggested by samples of children (aged 5-12 years; $n$ 96) and parents (of children aged 5-12 years; $n$ 186) from the island of Ireland, June-August 2011

\begin{tabular}{ll}
\hline Theme & Opportunities \\
\hline Cost & $\begin{array}{l}\text { Ensure healthier items are competitively priced against standard menu items } \\
\text { Include healthier items as standard with children's meals }\end{array}$ \\
Flexibility & $\begin{array}{l}\text { Provide a choice for each of the components of a children's meal } \\
\text { Provide a range of fresh meats including chicken breast, grilled burger, grilled fish fillet and a range of vegetables, } \\
\text { such as chopped raw vegetables, cabbage, carrots, peas, sweet corn, corn on the cob, broccoli } \\
\text { Allow children to try foods before they order }\end{array}$ \\
Portion sizes & $\begin{array}{l}\text { Platters and buffets with a range of different foods could encourage more children to try something new } \\
\text { Cooking methods }\end{array}$ \\
$\begin{array}{l}\text { Provide half portions of the adult's menu } \\
\text { Marketing }\end{array}$ & $\begin{array}{l}\text { Change current cooking methods to healthier alternatives, such as grilling, baking, steaming } \\
\text { Make healthier items and dishes appealing to children by using marketing techniques currently used by } \\
\text { establishments } \\
\text { Use sport to help motivate a healthier choice }\end{array}$ \\
\hline
\end{tabular}

their child's food choice decision. Younger children in particular were reported to be affected by attractive packaging or foods presented in shapes, as well as free toys and television advertisements. Children's peers were also considered by parents to affect children's food choices both positively and negatively, and parents themselves felt some pressure from children's peers to 'conform to the norm' (Table 5).

Parents did not consider that health played any role in a child's $\mathrm{OH}$ food choice decision despite their belief that children had a good awareness of nutrition from education in school.

Parent's contribution to out-of-home food choice decision Parents had strong feelings that $\mathrm{OH}$ eating should be a treat and was expected to be an enjoyable eating experience where parents can feel less guilty about relaxing normal food-related rules that they may have when eating at home (Table 5).

For parents 'wasting food', 'avoiding an argument' with their children and 'cost/value for money' were the other key factors that influenced what they would like their children to order OH (Table 5). After 'treat', these were on a similar priority level and were interrelated. For example, parents did not want children to order a menu item that was too expensive or was likely to result in plate waste (such as having a large portion size, food not liked), but compromises were made in the face of counter-argument by the child. Despite parents reporting that they would like to consider health for their children's food choices when eating $\mathrm{OH}$, health considerations were overshadowed by these priorities. Consequently, parents were less likely to encourage a healthier $\mathrm{OH}$ food choice if it was at odds with the child's choice or interfered with their own priorities (Table 5). Healthier items were associated by parents as not being good value for money and likely to increase the risk of food neophobia and food wastage. However, parents also discussed strategies they might use to encourage children to make small health compromises (Table 5).

\section{Opportunities for bealthier out-of-bome eating}

Healthier food choices for children when eating out of home Parents believed they had most responsibility for what children ate $\mathrm{OH}$ but that $\mathrm{OH}$ establishments also had a key role to play in supporting families by providing an appropriate selection of healthy, in addition to less healthy, options. While parents currently perceived $\mathrm{OH}$ eating as generally unhealthy, they did consider 'traditional', 'fresh', 'served with vegetables' and 'made from scratch' options as healthier alternatives for their children. Parents viewed half portions of the adult's menu as healthier alternatives to the children's menu and considered these were of better nutritional quality.

Strategies recommended for healthier out-of-home eating Parents, and in some cases children, discussed possible opportunities that establishments could employ to support families in making healthier food choices (Table 6). These centred around cost, flexibility of food establishments, more appropriate portion sizes for children, healthier cooking methods and marketing strategies for healthier foods.

Given that parents and older children were primarily influenced by cost when eating $\mathrm{OH}$, they would be more likely to consider healthier items if these were included as standard and were competitively priced against other menu items:

'Well I think if they include it [fruit and vegetables] as part of the child's meal then my youngest would probably eat it. But he won't choose the fruit over the fries.' (Parent)

'If they stuck vegetables on the side of the plate more, it would be more normal.' (Parent)

More flexibility was considered by parents as the most effective method of overcoming children's food neophobia $\mathrm{OH}$. Carveries, buffets and mixed platters were considered to allow children to try new foods without the concern of receiving an entire meal that they would not like:

'But it was so annoying and I mean I got to a stage where I would say to them can I just have a plain 
vegetable and they would say it is already made.' (Parent)

'I know when my kids eat more vegetables is when we go to a buffet style. There is a lovely Chinese where they will pick the different vegetables.' (Parent)

'See if they done little trial bites for the children and they could taste little bits of different things that would be good because they like to taste what we are eating.' (Parent)

Portion sizes were reported to be inconsistent between establishments and very often were too large for younger children but too small for older children. Providing a range of portion sizes for the children's menu would allow more appropriate portions to be served to children. Both parents and children would like more establishments to offer half portions of the adult menu to increase the choice provided:

'The 3-year-old and 8-year-old get the very same potion - a big mountain of chips and you know they're not going to eat it and I think it's a waste.' (Parent)

'If you just have your menu that reflects... a half portion of Caesar salad, half portion of spaghetti bolognaise, half portion of the roast of the day, you go in there and you would go in day after day because you get good value for money and it is education, sending out the right message to kids.' (Parent)

'Basically get the exact same meal [as the adult] in a smaller size right through the whole menu.' (Parent)

Parents assumed changing current cooking methods to grilling or baking would be a small compromise for establishments to improve the nutritional quality of current children's menus:

'Could they have a low-fat mayonnaise option or if they suggest that they could grill it for you instead of frying, or use a different kind of oil maybe.' (Parent)

'I wouldn't mind seeing something where they give you the option, would you like it fried or would you like it grilled.' (Parent)

Current marketing strategies, such as a free toy or attractive packaging, were suggested by parents for healthier menu items to attract and encourage children to select these:

'The way children watch TV now - they're trying to draw them in, if they could draw them in to healthier food.' (Parent)

'You go into the crisps [aisle] and there are nice bright packets and in the fruit [aisle] there is just a little plastic bag over the bananas. It is not really appealing for the kids in that way, the younger ones especially.' (Parent)

\section{Discussion}

This research has provided a unique insight into family experiences when eating $\mathrm{OH}$ from both parent/guardian and child perspectives. Parents believed food businesses could do more to support families to select healthier foods and highlighted potential opportunities that may improve the nutritional quality of $\mathrm{OH}$ food specifically targeted at children. However, improving the nutritional quality of $\mathrm{OH}$ food will be challenging as various issues need to be considered. Furthermore, initiatives will not be successful if the views of all relevant stakeholders are not considered.

The perception of $\mathrm{OH}$ eating as a treat was the most frequently mentioned factor by both parents and children. Irrespective of family demographics and what priority was placed on healthy eating in the home, health was considered less frequently in $\mathrm{OH}$ eating. Although 'a treat' may have connotations of being unhealthy, the challenge will be to ensure food that is healthier will also be perceived as a treat. There is a desire for parents to encourage their children to make healthier choices but only if the more important priorities are also met. Parents were more willing to consider health in regard to 'quality' of the food and believed establishments should give more focus to providing fresh meats, such as beef steak, chicken/fish fillets, as well as the more popular foods such as chicken nuggets and sausages. If the current menu items were cooked differently and were served with fruit, vegetables, yoghurt or milk, parents would view current children's menus as healthier.

This type of approach may also resonate with the catering industry which has been found to prefer small changes that customers will not notice, such as changing cooking methods or adding fruit and vegetables as opposed to reducing portion sizes to decrease the energy density ${ }^{(33)}$. Given that children did not apply their knowledge of health and food in food choice decisions, these small by stealth changes would not detract from the enjoyment of the meal and may prove to be some of the most effective strategies. Parents also considered that children had received nutrition knowledge in school, although this did not impact upon food choice decisions. This gap between knowledge and children's food choice decisions has been raised previously $^{(27,28)}$ and emphasises the mismatch between having the knowledge and putting it into practice.

The findings of this research are also fully supportive of Edwards, who emphasised the importance of considering not just food when eating $\mathrm{OH}$ but also the individual and his/her situation ${ }^{(39)}$. Parents will sacrifice the quality of food when eating $\mathrm{OH}$ for a stress-free, enjoyable experience. Thus food businesses that take these needs into account, in 
addition to the food on offer, will be more likely to attract families as customers. Similar to Warde and Martens, the present study also demonstrated that the $\mathrm{OH}$ eating experience begins before entering an establishment ${ }^{(40)}$. Parents considered the best type of establishment to patronise by determining if their children would maintain interest for the occasion: if their children were likely to be disruptive in a sit-down restaurant, parents would select a child-friendly fast-food establishment with a short service time.

Clear differences were identified between what parents and children described as influencing the child's food choice decision, with only one common theme being reported by both: 'the norm/food neophobia'. Parents reported healthier foods in particular were likely to induce feelings of rejection in children but they believed if establishments were more willing to meet children's special requests by being more flexible, such as avoiding any type of garnish and serving sauces separately, more children may be more likely to try new foods. Moreover, parents' confidence in children trying new foods may need to be increased given they were more concerned with avoiding food and money waste than health considerations. Smaller portions of the adult menus would be an excellent opportunity for increasing parents' trust that the meal will be enjoyed and promotes children eating the same foods as their parents in an environment where this tends not to happen ${ }^{(41)}$. Parents were strongly of the opinion that marketing greatly impacted upon children's food choice decisions, but it is interesting to note that children did not acknowledge this, as was previously shown in the home $^{(26,28)}$ and $\mathrm{OH}$ settings ${ }^{(42)}$. Parents in our study recommended using currently effective marketing techniques to promote healthier menu items in an effort to encourage children to try these, such as free toys and colourful packaging.

Given that cost is a high priority in food choice decisions by adults ${ }^{(43-45)}$ (and for children when purchasing their own $\mathrm{OH}$ food ${ }^{(26,28)}$, healthier foods are only likely to be selected in the $\mathrm{OH}$ setting if they are competitively priced. The preference was clearly for 'all in' pricing where a main course, side, drink and dessert were included in children's meals. If healthier items, such as fruit and vegetables, were included in this cost it is likely that more parents will encourage children to select/consume these healthier items. However, from the food businesses' perspective they may be reluctant to include healthier items if these are more expensive $^{(34)}$. Greater engagement with food businesses will be pivotal if they are to be persuaded to provide competitively priced healthier items without impacting overall profit margins. However, it will be of great benefit if they do to increase the family customer base.

Concurring with previous research, parents and children reported that in contrast to the home setting ${ }^{(26,42,46)}$, autonomy for choosing $\mathrm{OH}$ food begins at a much younger age $^{(27,42)}$. As a result, any efforts to encourage children to make healthier choices should be cognisant of the fact that children make food choices based predominantly on taste ${ }^{(26-29,47)}$. However, children's food choice decisions are even more complex in the $\mathrm{OH}$ environment given that while children have increased autonomy in the decision made, the process is bidirectional with parents. This highlights how imperative it is to consider both parents' and children's competing priorities in a public health intervention aimed at supporting healthier $\mathrm{OH}$ choices.

The main strength of this research has been the exploration of issues concerned with $\mathrm{OH}$ eating from both the parent's and child's perspective, and from a wide range of backgrounds across the island of Ireland. However, there are also acknowledged limitations. Although purposive sampling techniques were used to recruit participants in the interest of generating a rich data set, the study participants may not have been representative of the general population. The inclusion of a large number of discussion topics for parents and children may not have achieved a full exploration of each discussion topic but it has provided a good overview of the factors influencing current family $\mathrm{OH}$ eating practices.

\section{Conclusion}

In conclusion, the family $\mathrm{OH}$ eating environment is a unique and increasingly a key part of the food environment. At present $\mathrm{OH}$ eating occasions are largely perceived as a treat for all the family where although parents would like to consider health, it is not currently a priority for many parents and children. However, there are potential opportunities for food businesses to support families to make healthier decisions which will only serve to increase an establishment's attractiveness to families. The key changes highlighted by parents and children that may be most effective were increased choice, increased flexibility and a change to healthier cooking methods. Training for food businesses to create interesting, appealing and economically viable menu items that maintain the treat element of the occasion will be important to ensure the success of healthier $\mathrm{OH}$ eating. Of upmost importance, the entire family $\mathrm{OH}$ experience needs to be considered when developing public health interventions as these will not be effective if they do not acknowledge family priorities and expectations in this environment.

\section{Acknowledgements}

The authors dedicate this article to the memory of their colleague Professor Julie Wallace (7 April 1971-7 February 2012). Acknowledgements: The authors are grateful to the parents and children who participated in the study and to Nick Bohill (N.B.) and Dawn McCartney (D.M.) for their contribution towards moderating the pairs and groups. Financial support: This material is based upon works supported by safefood, the Food Safety Promotion Board (under grant number 10-2009). L.E.M. is supported by a 
PhD award from the Department of Employment and Learning, UK. safefood and the Department of Employment and Learning had no role in the design, analysis or writing of this article. Conflict of interest: None. Authorship: M.B.E.L., J.M.W.W., G.H. and A.L designed the study. G.H. and A.L. recruited participants and conducted the research. L.E.M. and R.K.P. attended qualitative sessions as note takers. L.E.M. and R.K.P. analysed the data and prepared the first draft of the manuscript. T.A.M., G.H. and A.L. critically reviewed the manuscript and approved the final version. M.B.E.L. led the research and finalised the manuscript. Ethics of human subject participation: The research was approved by the University of Ulster Research Ethics Committee (REC/11/0057).

\section{References}

1. Vandenbroeck P, Goossens J \& Clemens M (2007) Tackling obesities: future choices. http://www.bournemouth.gov.uk/ PlanningBuildings/Planning/Policy/Local-Plan/CoreStrategy/ CoreStrategyFiles/SubmissionFiles/BackgroundDocs/Website versions/3-17-TacklingObesitiesFutureChoices.pdf (accessed February 2014).

2. Kant AK \& Graubard BI (2004) Eating out in America, 19872000: trends and nutritional correlates. Prev Med 38, 243-249.

3. Adair LS \& Popkin BM (2005) Are child eating patterns being transformed globally? Obes Res 13, 1281-1299.

4. Department for Environment Food and Rural Affairs (2013) Family Food 2011. London: TSO.

5. Irish Universities Nutrition Alliance (2011) National Adult Nutrition Survey Summary Report. Dublin: IUNA.

6. Orfanos P, Naska A, Trichopoulou A et al. (2009) Eating out of home: energy, macro- and micronutrient intakes in 10 European countries. The European Prospective Investigation into Cancer and Nutrition. Eur J Clin Nutr 63, Suppl. 4, S239-S262.

7. O'Dwyer N, McCarthy S, Burke S et al. (2005) The temporal pattern of the contribution of fat to energy and of food groups to fat at various eating locations: implications for developing food-based dietary guidelines. Public Health Nutr 8, 249-257.

8. Lachat C, Nago E, Verstraeten R et al. (2012) Eating out of home and its association with dietary intake: a systematic review of the evidence. Obes Rev 13, 329-346.

9. Mancino L, Todd J, Guthrie J et al. (2010) How Food Away From Home Affects Children's Diet Quality. Washington, DC: USDA.

10. Larson N, Neumark-Sztainer D, Laska MN et al. (2011) Young adults and eating away from home: associations with dietary intake patterns and weight status differ by choice of restaurant. J Am Diet Assoc 111, 1696-1703.

11. Ayala GX, Rogers M, Arredondo EM et al. (2008) Away-from-home food intake and risk for obesity: examining the influence of context. Obesity (Silver Spring) 16, 1002-1008.

12. Bowman SA, Gortmaker SL, Ebbeling CB et al. (2004) Effects of fast-food consumption on energy intake and diet quality among children in a National Household Survey. Pediatrics 113, 112-118.

13. Rosenheck R (2008) Fast food consumption and increased caloric intake: a systematic review of a trajectory towards weight gain and obesity risk. Obes Rev 9, 535-547.

14. Fraser LK, Clarke GP, Cade JE et al. (2012) Fast food and obesity: a spatial analysis in a large United Kingdom population of children aged 13-15. Am J Prev Med 42, e77-e85.
15. Birch L, Fisher J \& Davison K (2003) Learning to overeat: maternal use of restrictive feeding practices promotes girls' eating in the absence of hunger. Am J Clin Nutr 78, 215-220.

16. Birch L \& Fisher J (1998) Development of eating behaviours among children and adolescents. Pediatrics 101, 539-549.

17. Patrick H \& Nicklas TA (2005) A review of family and social determinants of children's eating patterns and diet quality. J Am Coll Nutr 24, 83-92.

18. Provencher V, Perusse L, Bouchard L et al. (2005) Familial resemblance in eating behaviours in men and women from the Quebec Family Study. Obes Res 13, 1624-1629.

19. Johannsen D, Johannsen N \& Specker B (2006) Influence of parents' eating behaviours and child feeding practices on children's weight status. Obesity (Silver Spring) 14, 431-439.

20. Gillman M, Rifas-Shiman S, Frazier A et al. (2000) Family dinner and diet quality among older children and adolescents. Arch Fam Med 9, 235-240.

21. Neumark-Sztainer D, Hannon P, Story M et al. (2003) Family meal patterns: associations with sociodemographic characteristics and improved dietary intake among adolescents. J Am Diet Assoc 103, 317-322.

22. Taveras E, Rifas-Shiman S, Berkey C et al. (2005) Family dinner and adolescent overweight. Obes Res 13, 900-906.

23. Fulkerson JA, Story M, Neumark-Sztainer D et al. (2008) Family meals: perceptions of benefits and challenges among parents of 8- to 10-year-old children. J Am Diet Assoc 108, 706-709.

24. Singh AS, Mulder C, Twisk JWR et al. (2008) Tracking of childhood overweight into adulthood: a systematic review of the literature. Obes Rev 9, 474-488.

25. Irish Universities Nutrition Alliance (2005) The National Children's Food Survey. Dublin: IUNA.

26. Holsten JE, Deatrick JA, Kumanyika S et al. (2012) Children's food choice process in the home environment. A qualitative descriptive study. Appetite 58, 64-73.

27. Fitzgerald A, Heary C, Nixon E et al. (2010) Factors influencing the food choices of Irish children and adolescents: a qualitative investigation. Health Promot Int 25, 289-298.

28. McKinley MC, Lowis C, Robson PJ et al. (2005) It's good to talk: children's views on food and nutrition. Eur J Clin Nutr 59, 542-551.

29. Neumark-Sztainer D, Story M, Perry C et al. (1999) Factors influencing food choices of adolescents: findings from focus-group discussions with adolescents. J Am Diet Assoc 99, 929-937.

30. World Health Organization (2004) Global Stategy on Diet, Physical Activity and Health. Resolution of the Fifty-seventh World Health Assembly WHA57.17. Geneva: WHO.

31. World Health Organization (2007) Proposed Second WHO European Action Plan for Food and Nutrition Policy 20072012. Copenhagen: WHO Regional Office for Europe.

32. World Health Organization (2007) Factsheet: Second WHO European Action Plan for Food and Nutrition Policy: Tackling Noncommunicable and Acute Diseases. Copenhagen: WHO Regional Office for Europe.

33. Obbagy JE, Condrasky MD, Roe LS et al. (2011) Chefs' opinions about reducing the calorie content of menu items in restaurants. Obesity (Silver Spring) 19, 332-337.

34. Lachat C, Naska A, Trichopoulou A et al. (2011) Essential actions for caterers to promote healthy eating out among European consumers: results from a participatory stakeholder analysis in the HECTOR project. Public Health Nutr 14, 193-202.

35. McGuffin LE, Wallace JMW, McCrorie TA et al. (2013) Family eating out-of-home: a review of nutrition and health policies. Proc Nutr Soc 72, 126-139.

36. MacDonald R, Miell D \& Morgan L (2000) Social processes and creative collaboration in children. Eur J Psychol Educ 15, 405-415. 
37. Jones SC, Mannino N \& Green J (2010) 'Like me, want me, buy me, eat me': relationship-building marketing communications in children's magazines. Public Health Nutr 13, 2111-2118.

38. Braun V \& Clarke V (2006) Using thematic analysis in psychology. Qual Res Psychol 3, 77-101.

39. Edwards JSA (2012) The foodservice industry: eating out is more than just a meal. Food Qual Prefer 27, 223-229.

40. Warde A \& Martens L (2000) Eating Out: Social Differentiation, Consumption and Pleasure. Cambridge: Cambridge University Press.

41. Skafida V (2013) The family meal panacea: exploring how different aspects of family meal occurrence, meal habits and meal enjoyment relate to young children's diets. Sociol Health Illn 35, 906-923.

42. Warren E, Parry O, Lynch R et al. (2008) 'If I don't like it then I can choose what I want': Welsh school children's accounts of preference for and control over food choice. Health Promot Int 23, 144-151.
43. Ward P, Mamerow L, Henderson J et al. (2012) The social determinants of food purchasing practices: who chooses price-before-health, taste-before-price or organic foods in Australia? Food Nutr Sci 3, 461-470.

44. Glanz K, Basil M, Maibach E et al. (1998) Why Americans eat what they do: taste, nutrition, cost, convenience, and weight control concerns as influences on food consumption. J Am Diet Assoc 98, 1118-1126.

45. de Rezende DC \& de Avelar AES (2012) Factors that influence the consumption of food outside the home in Brazil. Int J Consum Stud 36, 300-306.

46. Bassett R, Chapman GE \& Beagan BL (2008) Autonomy and control: the co-construction of adolescent food choice. Appetite 50, 325-332.

47. Stevenson C, Doherty G, Barnett J et al. (2007) Adolescents' views of food and eating: identifying barriers to healthy eating. J Adolesc 30, 417-434.

48. Market Research Society (2010) Occupation Groupings: AJob Dictionary, 7th ed. London: The Market Research Society. 